\title{
Motivation and job satisfaction among medical and dental college faculty in Pakistan amid the COVID-19 outbreak
}

\author{
Saqib Ali ${ }^{\mathrm{a}}$, Beenish Fatima Alam ${ }^{\mathrm{b}, *}$, Sara Noreen ${ }^{\mathrm{c}}$, Madiha Anwar ${ }^{\mathrm{b}}$, \\ Sabeen Hashmat Qazi ${ }^{\mathrm{d}}$ and Talib Hussain ${ }^{\mathrm{e}}$ \\ ${ }^{a}$ Department of Biomedical Dental Sciences, College of Dentistry, Imam Abdulrahman Bin Faisal University, \\ Dammam, Saudi Arabia \\ ${ }^{\mathrm{b}}$ Department of Oral Biology, Bahria University Medical and Dental College, Karachi, Pakistan \\ ${ }^{\mathrm{c}}$ Department of Medicine, Khyber Teaching Hospital, Peshawar, Pakistan \\ ${ }^{\mathrm{d}}$ Department of Biochemistry, Jinnah Medical and Dental College, Karachi, Pakistan \\ ${ }^{\mathrm{e}}$ Department of Oral Biology, Women Medical and Dental College, Abbottabad, Pakistan
}

Received 22 September 2020

Accepted 23 April 2021

\begin{abstract}
.
BACKGROUND: The novel coronavirus (COVID-19) has affected economies all over the world. The ability of an organization to grow is heavily influenced by job satisfaction and employee motivation.

OBJECTIVE: This study examines the factors affecting employee motivation and job satisfaction among medical and dental college faculty members in Pakistan, both in the private and public sector, during the COVID-19 pandemic.

METHODS: Medical and dental college faculty in Pakistan comprised the sample for this multi-centric cross-sectional study. A questionnaire, which was modified from an existing study, was distributed electronically. A student's independent $t$-test was applied to compare the mean scores of the responses from public and private sector employees.

RESULTS: Of the 466 total respondents, $55 \%$ were female and $45 \%$ male. Public sector faculty reported receiving adequate resources and preferred online teaching. Both public and private sector faculty reported being satisfied with regular workshops and training. Private sector employees demonstrated more satisfaction with workplace safety measures. Public sector faculty highlighted the positive influence of job security and timely salary payments on productivity.

CONCLUSION: Faculty members from both the public and private sector find working from home to be easier and better for handling one's workload. Public sector faculty noted job security, timely salary payments, and an individual's sense of achievement as sources of motivation. Private institutes are more lacking in ensuring their faculty feel content and satisfied. Measures should be undertaken to improve the level of motivation felt by faculty members, especially in the private sector.
\end{abstract}

Keywords: Incentive, contentment, employees, pandemic, teaching

\footnotetext{
*Address for correspondence: Dr. Beenish Fatima Alam, Department of Oral Biology, Bahria University Medical and Dental College, Karachi, Pakistan. Tel.: +923322616390; E-mail: nish_alam@yahoo.com.
}

\section{Introduction}

Job satisfaction can be defined as a constellation of an individual's attitudes towards or about a certain job [1]. Herzberg and colleagues formulated the two-factor theory regarding job satisfaction by distinguishing intrinsic motivational factors-comprised 
primarily of acknowledgment, work-related responsibilities, and accountability-from extrinsic factors, such as job security, an adequate working environment, and remuneration. This theory was reinforced by Sanjeev and colleagues, who asserted that the two-factor structure consists of motivation and satisfaction [2]. Job satisfaction and an attractive work environment are the intrinsic motivational factors that influence job performance, while financial rewards are the extrinsic factors [3]. The importance of teacher satisfaction and engagement at work should be ensured because these factors positively influence job performance [4].

Since the novel coronavirus (COVID-19) was declared a pandemic, it has affected countries worldwide [5]. Its impacts have had a dramatic influence on people's everyday lives, affecting health, family life, political situations, and safety. In many countries, health authorities have imposed lockdowns and social distancing protocols to flatten the curve of infection [6]. Universities, including medical and dental schools, have halted traditional classes and switched to online learning [7]. For organizations, the pandemic has caused changes in working styles and affected human collaboration [8]. Consequently, many companies have been forced to downsize, with many workers losing their jobs [9]. Many of those still with jobs must now work from home or take unpaid leave [10]. Others are subject to physical or mental stress at the thought of bringing the coronavirus home to family members. In many cases, workers show dissatisfaction or unwillingness to consent to poor working conditions, especially in companies that did not cultivate healthy employee environments during normal times [11].

Pakistan is a developing country, according to the World Health Organization's Regional Office for the Eastern Mediterranean (WHO EMRO). It has a population of roughly 188.9 million and ranks 147 of the 188 nations in the human development index [12]. Many of the healthcare personnel within the country are not happy with their earnings and feel that their quality of life is poor compared to developed countries [13]. Job satisfaction has been observed to significantly affect employees, which in turn affects the efficacy of the institute [14].

According to the Existence Relatedness Growth concept, an individual has three sets of elementary needs: existence, relatedness, and progression [15]. In cases where attempts to meet these needs with high precedence are not successful, individuals will turn their focus to things that initially were less important. This often leads to frustration and dissatisfaction.

According to the WHO, there exists an overall concern regarding the scarcity of human resources in healthcare [16]. Job dissatisfaction is an important indicator of an employee's intention to leave their job [17]. Institutions that understand the factors affecting the satisfaction of faculty members are more likely to achieve improved performance from their employees. Therefore, the objectives of the present study are to evaluate job satisfaction among medical and dental college faculty members in Pakistan to determine what most affects their job satisfaction and motivation, as well as to identify specific concerns arising during the pandemic.

\section{Methods}

This multi-centric cross-sectional survey was conducted among faculty members at public and private medical and dental institutes in Pakistan. Informed consent was obtained from all participating members before beginning the study. Responses were kept anonymous to maintain confidentiality.

\subsection{Ethical approval}

Formal approval of the study was obtained from the Bahria University Medical and Dental College Ethics Review Committee before starting the study (approval no. ERC 56/2020), per the Declaration of Helsinki.

\subsection{Questionnaire development}

The questionnaire used for this research was modified from a Nigerian study that focused on library faculty [18]. It was pilot-tested with a sample of 30 medical and dental college faculty members to test the reliability and validity of the questions asked. The faculty members who participated in the pilot test were excluded from the formal study. Any necessary corrections were completed before distributing the survey. The questions were tested via Statistical Package for Social Sciences (SPSS, v23) using a bivariate correlation.

A Cronbach's alpha coefficient was performed to determine the internal constancy and reliability for the tested survey form. It was found to be 0.76 , which was acceptable. Job satisfaction and motivation factors were indicated on a six-point Likert scale, where 
1 represented "strongly disagree," 2 "disagree," 3 "slightly disagree," 4 "slightly agree," 5 "agree" and 6 "strongly agree."

The survey was divided into three sections. The first focused on the demographic details of the participants, which included age, gender, field, their department of employment, and total years of employment. The second section contained twelve questions about job motivation and the current pandemic's effect on promotions, online teaching, managing workloads, and job satisfaction. The last section consisted of questions to assess job satisfaction, evaluate the faculty members' experiences of anxiety about the future and job security, and determine the role of reimbursement and workshops on improving working efficiency.

\subsection{Sample and data collection}

The present study was conducted in medical and dental institutes throughout Pakistan. Faculty members willing to participate were included, while those who did not give consent or were away on long leaves were excluded from the study. The questionnaire was distributed via social media and email through convenience sampling. One faculty member from each organization was nominated to disseminate the questionnaire through their institute.

\subsection{Statistical analysis}

Data was analyzed using SPSS (v23) for Windows. Descriptive analyses were performed using frequency, mean, and standard deviation values. A student's independent $t$-test was used to compare the mean scores of the questionnaire responses between faculty respondents from public and private sector universities.

\section{Results}

A total of 500 questionnaires were sent out via social media platforms and email. From these, 466 responses were received, providing a response rate of $93 \%$. Of the sample, $55 \%$ were female and $45 \%$ were male. The mean age of the participants was $33.7 \pm 7.4$ years. Approximately 52\% of the respondents worked in private sector colleges, while the remaining $48.5 \%$ were employed by public sector institutes. Most of the participants were medical faculty $(50.6 \%, n=236)$, and $49.4 \%(n=230)$ were
Table 1

Demographics of the study participants

\begin{tabular}{lc}
\hline Age $($ Mean $\pm v S D)$ & $33.7 \pm v 7.4$ \\
Gender & $\mathbf{N}(\%)$ \\
Males & $208(44.6 \%)$ \\
Females & $258(55.4 \%)$ \\
University & \\
Public sector & $226(48.5 \%)$ \\
Private sector & $240(51.5 \%)$ \\
Faculty & \\
Medical & $236(50.6 \%)$ \\
Dental & $230(49.4 \%)$ \\
Designation & \\
Lecturer & $300(64.4 \%)$ \\
Asst. Prof. & $102(21.9 \%)$ \\
Assoc. Prof. & $36(7.7 \%)$ \\
Professor & $28(6.0 \%)$ \\
Years of service & \\
1-5 years & $310(66.5 \%)$ \\
6-10 years & $90(19.3 \%)$ \\
11-15 years & $32(6.9 \%)$ \\
more than 15 years & $34(7.3 \%)$ \\
\hline
\end{tabular}

dental faculty. Among these, $64.4 \%(n=300)$ were lecturers, $30 \%(n=102)$ were assistant professors, $7.7 \%(n=36)$ were associate professors, and 6\% $(n=28)$ were professors. The number of respondents who had served in their institutions between 1 and 5 years was $66.5 \%(n=310), 19.3 \%(n=90)$ had served between 6 and 10 years, $6.9 \%(n=32)$ had served 11 to 15 years, and $7.3 \%(n=34)$ had served for more than 15 years (see Table 1 ).

The relationship of each employee with their level of motivation for their job during the COVID-19 pandemic is described in Table 2. The highest mean score was exhibited by medical faculty $(4.4 \pm 0.9$, $\mathrm{p}$ 0.0001) employed in the public sector. These respondents indicated that the pandemic provides a source of challenge, that they are better able to balance workload and family life $(4.3 \pm 0.9, \mathrm{p} 0.002)$, and that the unique circumstances have provided more opportunities to expand their teaching abilities $(4.2 \pm 0.9, \mathrm{p}-0.004)$. For the dental faculty employed in the public sector, the highest mean score was $(4.3 \pm 1.4, \mathrm{p} 0.003)$. These respondents identified that they found working from home easier and beneficial.

Significant differences in which respondents found working from home to be easier were noted between public medical ( $3.6 \pm 1.5 \mathrm{p} 0.01)$ and dental $(3.09 \pm 1.5 \mathrm{p} 0.01)$ faculty and private medical $(4.3 \pm 1.4$ p 0.003$)$ and dental $(3.2 \pm 1.5$ p 0.003$)$ employees. A similar trend regarding the ability to balance one's workload and family life was noted between public medical ( $4.3 \pm 0.9 \mathrm{p} 0.002)$ and dental $(3.7 \pm 1.4 \mathrm{p} 0.002)$ employees and private medical 
Table 2

Factors affecting motivation of faculty members within private and public universities

\begin{tabular}{|c|c|c|c|c|}
\hline \multirow[t]{2}{*}{ Question } & \multicolumn{2}{|c|}{ Public sector } & \multicolumn{2}{|c|}{ Private sector } \\
\hline & Mean \pm S.D & $p$-value & Mean \pm S.D & $p$-value \\
\hline \multicolumn{5}{|c|}{ Chances of promotion are affected by the current pandemic situation } \\
\hline Medical & $3.8 \pm 1.1$ & \multirow[t]{2}{*}{0.19} & $3.7 \pm 1.1$ & \multirow[t]{2}{*}{0.5} \\
\hline Dental & $3.5 \pm 1.2$ & & $3.6 \pm 1.1$ & \\
\hline \multicolumn{5}{|c|}{ Working from home easier and more effective } \\
\hline Medical & $3.6 \pm 1.5$ & \multirow[t]{2}{*}{$0.01^{*}$} & $4.3 \pm 1.4$ & \multirow[t]{2}{*}{$0.003^{*}$} \\
\hline Dental & $3.09 \pm 1.5$ & & $3.2 \pm 1.5$ & \\
\hline \multicolumn{5}{|c|}{ Able to handle to workload and family life } \\
\hline Medical & $4.3 \pm 0.9$ & \multirow[t]{2}{*}{$0.002^{*}$} & $3.8 \pm 1.3$ & \multirow[t]{2}{*}{$<0.001^{* *}$} \\
\hline Dental & $3.7 \pm 1.4$ & & $3.8 \pm 1.3$ & \\
\hline \multicolumn{5}{|c|}{ Better opportunities to explore my teaching abilities } \\
\hline Medical & $4.2 \pm 0.9$ & \multirow[t]{2}{*}{$0.004^{*}$} & $3.7 \pm 1.3$ & \multirow[t]{2}{*}{0.6} \\
\hline Dental & $3.8 \pm 1.4$ & & $3.6 \pm 1.4$ & \\
\hline \multicolumn{5}{|c|}{ A sense of challenge and achievement } \\
\hline Medical & $4.4 \pm 0.9$ & \multirow[t]{2}{*}{$0.008^{*}$} & $4.3 \pm 0.8$ & \multirow[t]{2}{*}{0.3} \\
\hline Dental & $4.0 \pm 1.1$ & & $4.1 \pm 0.9$ & \\
\hline \multicolumn{5}{|c|}{ Opinion respected by the head } \\
\hline Medical & $4.1 \pm 1.2$ & \multirow[t]{2}{*}{0.25} & $3.9 \pm 1.2$ & \multirow[t]{2}{*}{0.15} \\
\hline Dental & $3.9 \pm 1.1$ & & $4.0 \pm 1.2$ & \\
\hline \multicolumn{5}{|c|}{ Positive recognition of the efforts by the head } \\
\hline Medical & $4.4 \pm 0.9$ & \multirow[t]{2}{*}{0.4} & $4.1 \pm 1.2$ & \multirow[t]{2}{*}{0.17} \\
\hline Dental & $4.3 \pm 1.0$ & & $4.3 \pm 1.1$ & \\
\hline \multicolumn{5}{|c|}{ Treated in a considerate manner by the head } \\
\hline Medical & $4.3 \pm 0.9$ & \multirow[t]{2}{*}{0.15} & $4.1 \pm 1.1$ & 0.9 \\
\hline Dental & $4.1 \pm 1.2$ & & $4.1 \pm 1.2$ & \\
\hline Negative att & the head have & y ability & & \\
\hline Medical & $4.3 \pm 0.9$ & 0.09 & $4.2 \pm 0.9$ & 0.8 \\
\hline Dental & $4.1 \pm 1.1$ & & $4.3 \pm 1.1$ & \\
\hline Anxious abc & ature in the fiel & & & \\
\hline Medical & $4.3 \pm 0.9$ & 0.09 & $4.1 \pm 1.0$ & 0.5 \\
\hline Dental & $4.1 \pm 1.1$ & & $4.0 \pm 1.2$ & \\
\hline Anxious abc & e employment & ies & & \\
\hline Medical & $4.3 \pm 0.8$ & 0.12 & $4.1 \pm 0.9$ & $0.02^{*}$ \\
\hline Dental & $4.1 \pm 1.1$ & & $3.8 \pm 1.2$ & \\
\hline Prefer onlin & ag over traditio & -face lect & & \\
\hline Medical & $4.3 \pm 1.1$ & $0.001^{*}$ & $4.1 \pm 1.3$ & $0.04^{*}$ \\
\hline Dental & $3.6 \pm 1.6$ & & $3.7 \pm 1.6$ & \\
\hline Friendship v & colleagues is a & level as b & oandemic & \\
\hline Medical & $3.8 \pm 1.5$ & 0.9 & $3.8 \pm 1.3$ & 0.9 \\
\hline Dental & $3.8 \pm 1.4$ & & $3.8 \pm 1.4$ & \\
\hline
\end{tabular}

$(3.8 \pm 1.3 \mathrm{p} 0.001)$ and dental $(3.8 \pm 1.3 \mathrm{p} 0.001)$ faculty members. Private medical ( $4.1 \pm 0.9 \mathrm{p} 0.02)$ and dental ( $3.8 \pm 1.2 \mathrm{p} 0.02)$ faculty reported being anxious about their future employment opportunities. Both public medical $(4.3 \pm 1.1 \mathrm{p} 0.001)$ and dental $(3.6 \pm 1.6 \mathrm{p} 0.001)$ faculty members and private medical $(4.1 \pm 1.3$ p 0.04$)$ and dental $(3.7 \pm 1.6$ p 0.04$)$ members agreed on delivering online lectures.

Table 3 presents the respondents' job satisfaction levels. Public medical $(3.7 \pm 1.4 \mathrm{p} 0.03)$ and dental $(3.6 \pm 1.2 \mathrm{p} 0.03)$ faculty reported receiving adequate resources. Both public medical (4.2 $\pm 0.9 \mathrm{p} 0.06)$ and dental (3.8 $\pm 1.4 \mathrm{p} 0.06)$ participants and private medical $(3.9 \pm 1.1 \mathrm{p} 0.001)$ and dental $(3.4 \pm 1.5 \mathrm{p}$ $0.001)$ faculty members attested to being provided with regular workshops and training. Private medical $(3.3 \pm 1.5 \mathrm{p} 0.03)$ and dental ( $3.9 \pm 1.5 \mathrm{p} 0.03)$ faculty were more satisfied with the safety measures taken by management to tackle COVID-19, while public medical $(4.4 \pm 0.8$ p 0.01$)$ and dental $(4.3 \pm 1.0$ p 0.01$)$ faculty noted the positive influence of job security on their productivity and were satisfied with receiving timely salary payments.

\section{Discussion}

This is one of the first studies to evaluate the level of satisfaction and motivation of medical and dental college faculty members in Pakistan during the 
Table 3

Factors affecting job satisfaction of faculty members

\begin{tabular}{|c|c|c|c|c|}
\hline \multirow[t]{2}{*}{ Question } & \multicolumn{2}{|c|}{ Public sector } & \multicolumn{2}{|c|}{ Private sector } \\
\hline & Mean \pm S.D & $p$-value & Mean \pm S.D & $p$-value \\
\hline \multicolumn{5}{|c|}{ University provided resources } \\
\hline Medical & $3.7 \pm 1.4$ & \multirow[t]{2}{*}{$0.03^{*}$} & $3.8 \pm 1.3$ & \multirow[t]{2}{*}{0.4} \\
\hline Dental & $3.6 \pm 1.2$ & & $3.9 \pm 1.2$ & \\
\hline \multicolumn{5}{|c|}{ Regular workshops and training for the conduction of lectures } \\
\hline Medical & $4.2 \pm 0.9$ & \multirow[t]{2}{*}{$0.06^{*}$} & $3.9 \pm 1.1$ & \multirow[t]{2}{*}{$0.001^{*}$} \\
\hline Dental & $3.8 \pm 1.4$ & & $3.4 \pm 1.5$ & \\
\hline \multicolumn{5}{|c|}{ Satisfactory measures taken by the management to tackle the current situation } \\
\hline Medical & $3.5 \pm 1.5$ & \multirow[t]{2}{*}{0.8} & $3.3 \pm 1.5$ & \multirow[t]{2}{*}{$0.03^{*}$} \\
\hline Dental & $3.6 \pm 1.5$ & & $3.9 \pm 1.5$ & \\
\hline \multicolumn{5}{|c|}{ Job security positively impacts the performance } \\
\hline Medical & $4.4 \pm 0.8$ & \multirow[t]{2}{*}{$0.01^{*}$} & $4.4 \pm 0.8$ & \multirow[t]{2}{*}{0.24} \\
\hline Dental & $4.3 \pm 1.0$ & & $4.3 \pm 1.1$ & \\
\hline \multicolumn{5}{|c|}{ Timely payment of the wages } \\
\hline Medical & $4.1 \pm 1.0$ & \multirow[t]{2}{*}{$0.02^{*}$} & $3.9 \pm 1.2$ & \multirow[t]{2}{*}{0.5} \\
\hline Dental & $4.3 \pm 1.2$ & & $4.1 \pm 1.3$ & \\
\hline
\end{tabular}

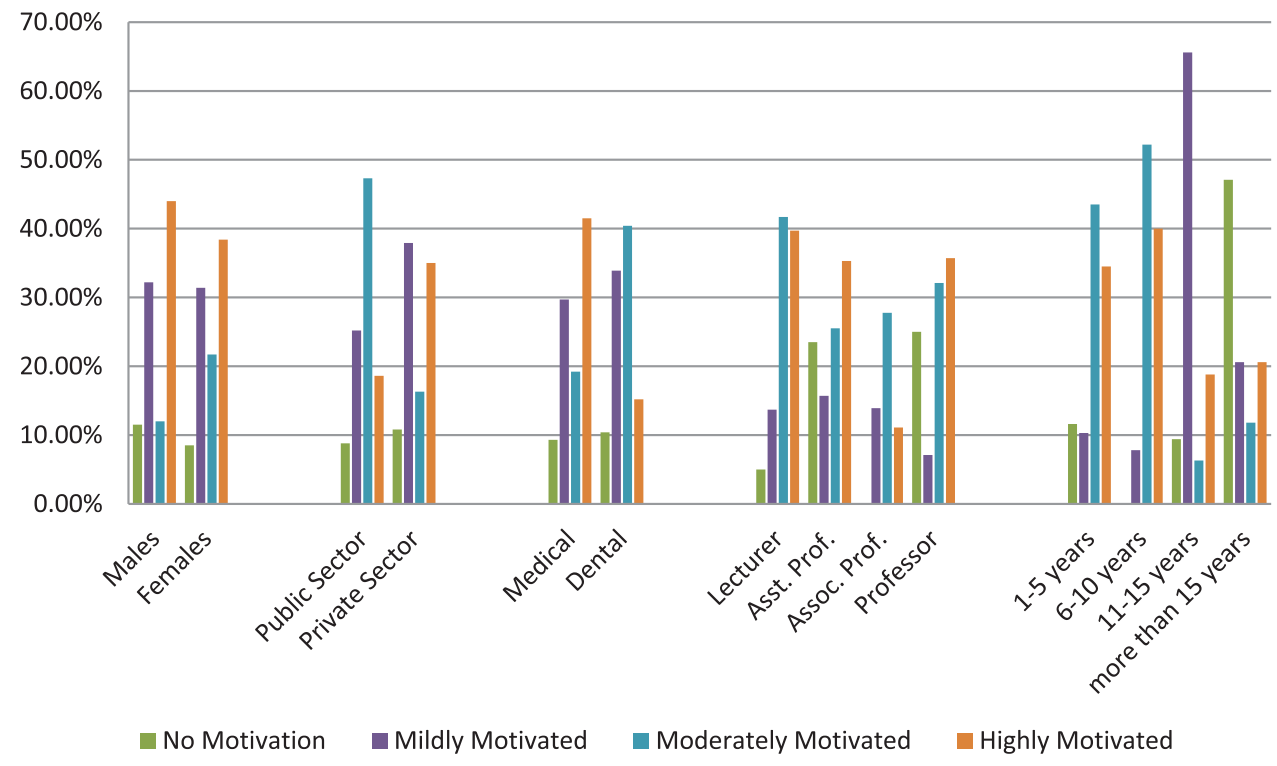

Fig. 1. Demonstrates the motivation level of faculty members.

COVID-19 pandemic. A high response rate of 93\% was achieved for this study.

As shown in Fig. 1, the male participants were generally more motivated for work than the female respondents. Participants from private institutes were observed to be more motivated with their jobs, possibly for monetary reasons, and medical faculty displayed a higher level of motivation than did the dental faculty. Lecturers exhibited higher levels of motivation, possibly because they were at start of their careers, followed by assistant professors and professors. Those with 6 to 10 years of experience showed higher motivation than the other experience groups.

A trend was noted that the current pandemic conditions raised concerns regarding finances and job security [19]. Another consequence of the pandemic is that many of the surveyed respondents are now working from home and having to learn to balance their work and family lives. The study results revealed that both public and private medical faculty overwhelmingly preferred working from home because they found it easier. These results are in contrast to those by Sethi et al., who report that healthcare 
workers find it difficult to cope with household work along with daily office work [20]. A possible explanation for this difference is that delivering lectures online provides a flexible teaching model for instructors, especially women, in the Pakistani population.

The sudden outbreak of COVID-19 led institutes around the world to impose strict safety measures to slow the spread of infection [21]. The current study demonstrates a significant agreement among medical and dental faculty in private Pakistani institutions toward the decision of universities to halt their physical operations. Similar findings were reported by Samarasekera et al., who observed favorable responses to universities' decisions to close all oncampus activities except a few selective faculties [22].

Since the outbreak of COVID-19, classes worldwide have switched to online formats to limit the virus' transmission. Results from the present study show that public faculty members were keen to teach online, they enjoyed a sense of achievement after completing their tasks, and they felt that the challenge of the new environment was causing their teaching abilities to improve. These results echo the findings of Yang et al., who observed that most of the teachers they surveyed in China were in favor of online teaching and felt that it provided a conducive platform for delivering information to students [23]. Moreover, it is expected that this new wave of online teaching will permanently change the former physical learning pattern and provide students new challenges for self-directed learning and self-organization.

Medical and dental participants from both public and private sector universities preferred online teaching over traditional formats. This can be attributed to the fact that teaching from home provides ease in delivering lectures. Similar results were reported previously by Duraku et al., who observed that the pandemic has taught instructors the benefits of online teaching, such as more flexibility and better conditions for keeping students engaged [24]. Moreover, effective online education both necessitates the adaptation of traditional classroom pedagogy while also helping teachers to develop new strategies.

Most of the public faculty members in the present study were satisfied with their institution's provision of adequate resources for conducting lectures online. Many institutes held training sessions to familiarize the faculty with the software required for online teaching. These outcomes reflect those of $\mathrm{Vu}$ et al., who reported that Vietnamese teachers attested to receiving adequate support from their school management and related bodies [25]. The present study's participants also showed a positive response to their institutions' provision of workshops and training sessions to help them move their teaching spaces online, both in the public and private sphere. These results are in contrast with other studies, where participants highlighted the need for courses and training sessions to teach them how to carry out lectures online [26, 27]. Such results indicate that circumstantial changes need to be implemented within curricula.

A statistically significant trend was noted of private medical and dental faculty members reporting anxiety about future employment opportunities during the pandemic. These findings resemble those of a prior study in Greece, in which workers exhibited higher levels of stress and anxiety when placed at risk of losing their jobs [28]. According to Lucky et al., job security is a key motivator for employees to remain in their jobs, regardless of national economies. Conversely, worries about job security often result in unprofessional or unproductive behavior [29]. The current study found a strong correlation between job security and high employee satisfaction in the public sector; this is likely because most public sector faculty members are permanent employees. Similar results were reported previously by Song et al., who found that government employees (i.e., protected) exhibited a higher level of job satisfaction and had better work engagement [30].

\section{Limitations}

Although the sample was collected from different medical and dental colleges in Pakistan, it cannot be said with authority that faculty members from every institute participated. Further, faculty members from some institutes responded in high numbers, and others in low numbers. Faculty members who were on leave were excluded from the study, which introduces the possibility of selection bias.

\section{Conclusion}

Medical and dental faculty members from both public and private institutions found that working from home was easier and enabled them to better handle their workloads. Faculty members from the public sector agreed that lockdown measures had provided better teaching opportunities and a positive challenge. Those from the private sector were more satisfied with the safety measures their institutions put in place, 
while public employees identified job security and the timely payment of wages as playing a key role in motivating them for work.

In terms of limitations, private organizations were found to be generally lacking in making their employees feel content and satisfied at work. In addition, private faculty members reported experiencing more anxiety about job security. These results indicate that measures should be taken to improve employee motivation, better ensure job security, and pay wages in a timely manner.

\section{Conflict of interest}

None to report.

\section{References}

[1] Ahmad KZ, Alwee SH, Yusoff ZZ, Osman SI, Tuah SN. The Association between Ethical Decision-Making, Job Satisfaction, Organisational Commitment and Selected Demographic Variables. Malaysian Management Journal. 2020; 7(2):1-1.

[2] Sanjeev MA, Surya AV. Two factor theory of motivation and satisfaction: An empirical verification. Annals of Data Science. 2016;3(2):155-73.

[3] Nica E, Potcovaru AM. The Impact of Motivation on the Work Performance in Health System. In Proceedings of the international management conference 2019 (Vol. 13, No. 1, pp. 913-918). Faculty of Management, Academy of Economic Studies, Bucharest, Romania.

[4] Park KA, Johnson KR. Job Satisfaction, Work Engagement, and Turnover Intention of CTE Health Science Teachers. International Journal for Research in Vocational Education and Training. 2019;6(3):224-42.

[5] Ali S, Noreen S, Farooq I, Bugshan A, Vohra F. Risk assessment of health care workers at the frontline against COVID-19. Pakistan Journal of Medical Sciences. 2020;36 (COVID19-S4):S99-S103.

[6] Naddeo A, Califano R, Fiorillo I. Identifying factors that influenced wellbeing and learning effectiveness during the sudden transition into eLearning due to the COVID-19 lockdown. Work. 2021;68(1):45-67.

[7] Sarfaraz S, Ahmed N, Abbasi MS, Sajjad B, Vohra F, Alhamdan RS, Maawadh AA, Al-Hamoudi N, Mokeem S, Aldahiyan N, Abduljabbar T. Self-perceived competency of the medical faculty for E-Teaching during the COVID-19 pandemic. Work. 2020;67:791-8.

[8] Mustajab D, Bauw A, Rasyid A, Irawan A, Akbar MA, Hamid MA. Working From Home Phenomenon As an Effort to Prevent COVID-19 Attacks and Its Impacts on Work Productivity. TIJAB (The International Journal of Applied Business). 2020;4(1):13-21.

[9] Chinazzi M, Davis JT, Ajelli M, Gioannini C, Litvinova M, Merler S, y Piontti AP, Mu K, Rossi L, Sun K, Viboud C. The effect of travel restrictions on the spread of the 2019 novel coronavirus (COVID-19) outbreak. Science. 2020; 368(6489):395-400.
[10] McKibbin WJ, Fernando R. The global macroeconomic impacts of COVID-19: Seven scenarios. Asian Economic Papers. 2020;2:1-55.

[11] Shan C, Tang DY. The value of employee satisfaction in disastrous times: Evidence from Covid-19. 2020 Mar 25 Available at SSRN 3560919.

[12] Jahan S. Human development report 2016-human development for everyone. 2017 Aug.

[13] Dodani S, LaPorte RE. Brain drain from developing countries: How can brain drain be converted into wisdom gain? J R Soc Med. 2005;98(11):487-91.

[14] Chen X, Liu M, Liu C, Ruan F, Yuan Y, Xiong C. Job Satisfaction and Hospital Performance Rated by Physicians in China: A Moderated Mediation Analysis on the Role of Income and Person-Organization Fit. International Journal of Environmental Research and Public Health. 2020;17(16):5846.

[15] Alderfer CP. Existence, Relatedness, and Growth: Human Needs in Organizational Settings. New York: Free Press; 1972.

[16] Singh T, Kaur M, Verma M, Kumar R. Job satisfaction among health care providers: A cross-sectional study in public health facilities of Punjab, India. Journal of Family Medicine and Primary Care. 2019;8(10):3268.

[17] Ojakaa D, Olango S, Jarvis J. Factors affecting motivation and retention of primary health care workers in three disparate regions in Kenya. Human Resources for Health. 2014;12(1):1-3.

[18] Ademodi DT, Akintomide OA. A Comparative study of levels of job satisfaction among librarians in private and public universities in Ondo State. Journal of Information and Knowledge Management. 2015;5(11):1-9.

[19] Ali S, Farooq I, Abdelsalam M, Alhumiad J. Current clinical dental practice guidelines and the financial impact of COVID-19 on dental care providers. European Journal of Dentistry. 2020;14 (S 01):S140-S145.

[20] Sethi BA, Sethi A, Ali S, Aamir HS. Impact of Coronavirus disease (COVID-19) pandemic on health professionals. Pakistan Journal of Medical Sciences. 2020;36 (COVID 19-S4).

[21] Farooq I, Ali S, Moheet, IA, AlHumaid J. COVID-19 outbreak, disruption of dental education, and the role of teledentistry. Pakistan Journal of Medical Sciences. 2020; 36(7):1726-31.

[22] Samarasekera DD, Goh DL, Yeo SP, Ngiam NS, Aw MM, Lim MM, Pillai S, Lee SS, Mahadevan M, Kow A, Chong YS. Response and Lessons Learnt Managing the COVID19 Crisis by School of Medicine, National University of Singapore. MedEdPublish. 2020;9(1):92.

[23] Yang X. Teachers' Perceptions of Large-Scale Online Teaching As an Epidemic Prevention and Control Strategy in China. ECNU Review of Education. 2020;3(4): 739-44.

[24] Duraku ZH, Hoxha L. The impact of COVID-19, school closure, and social isolation on gifted students' wellbeing and attitudes toward remote (online) learning. Preprint.

[25] Vu CT, Hoang AD, Than VQ, Nguyen MT, Dinh VH, Le QA, Le TT, Pham HH, Nguyen YC. Dataset of Vietnamese teachers' perspectives and perceived support during the COVID-19 pandemic. Data in brief. 2020;31:105788.

[26] La V-P, Pham T-H, Ho M-T, Nguyen M-H, P Nguyen K-L, Vuong T-T, et al. Policy response, social media and science journalism for the sustainability of the public health system amid the COVID-19 outbreak: The vietnam lessons. Sustainability. 2020;12(7):2931. 
[27] Ferdig RE, Baumgartner E, Hartshorne R, KaplanRakowski R, Mouza C. Teaching, technology, and teacher education during the covid-19 pandemic: Stories from the field. Waynesville, NC, USA: Association for the Advancement of Computing in Education (AACE). 2020.

[28] Nella D, Panagopoulou E, Galanis N, Montgomery A, Benos A. Consequences of job insecurity on the psychological and physical health of Greek civil servants. BioMed Research International. 2015;2015:67323.
[29] Lucky EO, Minai MS, Rahman HA. Impact of job security on the organizational performance in a multiethnic environment. Research Journal of Business Management. 2013;7(1):64-70.

[30] Song L, Wang Y, Li Z, Yang Y, Li H. Mental Health and Work Attitudes among People Resuming Work during the COVID-19 Pandemic: A Cross-Sectional Study in China. International Journal of Environmental Research and Public Health. 2020;17(14):5059. 